\title{
The Competency Requirements for HR Practitioners in Domestic Firms and
}

Multinational Enterprises

Karen Lo, Keith Macky \& Edwina Pio AUT University, New Zealand 


\section{Research Aim}

- To investigate HR competencies required for HR practitioners for their success in domestic firms and multinational enterprises (MNEs)

- Adopts a situationalist competency perspective which focuses on the contextual nature of HR competencies by differentiating between generic HR competencies (i.e., universally applicable to HR practitioners) and context-specific HR competencies (i.e., relevant to a narrower range of settings) 


\section{Situationalist Perspective}

- Challenges the universalist perspective that focuses on identifying generic HR competencies (Ulrich et al., 2013; Long \& Wan Ismail, 2009; Dainty, 2011)

- Argues that there are context-specific HR competencies as well as generic ones (Caldwell, 2008; 2010; Graham \& Tarbell, 2006; Roehling et al., 2005)

- The HR literature suggests that MNEs are likely to promote a more strategic HR role (Björkman, Ehrnrooth, Smale \& John, 2011; Sheehan \& Scalfidi, 2005; Sumelius, Bjorkman, \& Smale, 2008) and standardisation of HRM practices (Belizon, Gunnigle, \& Morley, 2013; Farndale \& Paauwe, 2005; Stiles \& Trevor, 2006) than domestic firms 


\section{Methodology}

\section{Research Question:}

What are the generic and context-specific HR competencies for domestic firms and MNEs?

\section{Mixed Method Research Design}

Phase 1:
Content Analysis
HR Job Descriptions
$\begin{gathered}\text { Phase 2: } \\ \text { Concept Mapping } \\ \text { Focus Groups }\end{gathered}$
Concept Mapping
Online Survey




\section{Concept Mapping Process}

\section{Step 1: Brainstorming Focus Groups}

3 focus groups of 8 focus group HR participants +2 HR experts brainstormed a list of $44 \mathrm{HR}$ competencies

Step 2: Concept Mapping Online Survey

63 New Zealand HR practitioners sorted and rated the HR competencies

Step 3: Concept Mapping Analysis

Concept System software was used to produce concept maps

Step 4: Interpretation of Concept Maps

Researcher reviewed groupings and names of the clusters 


\section{HR Competency Concept Map}

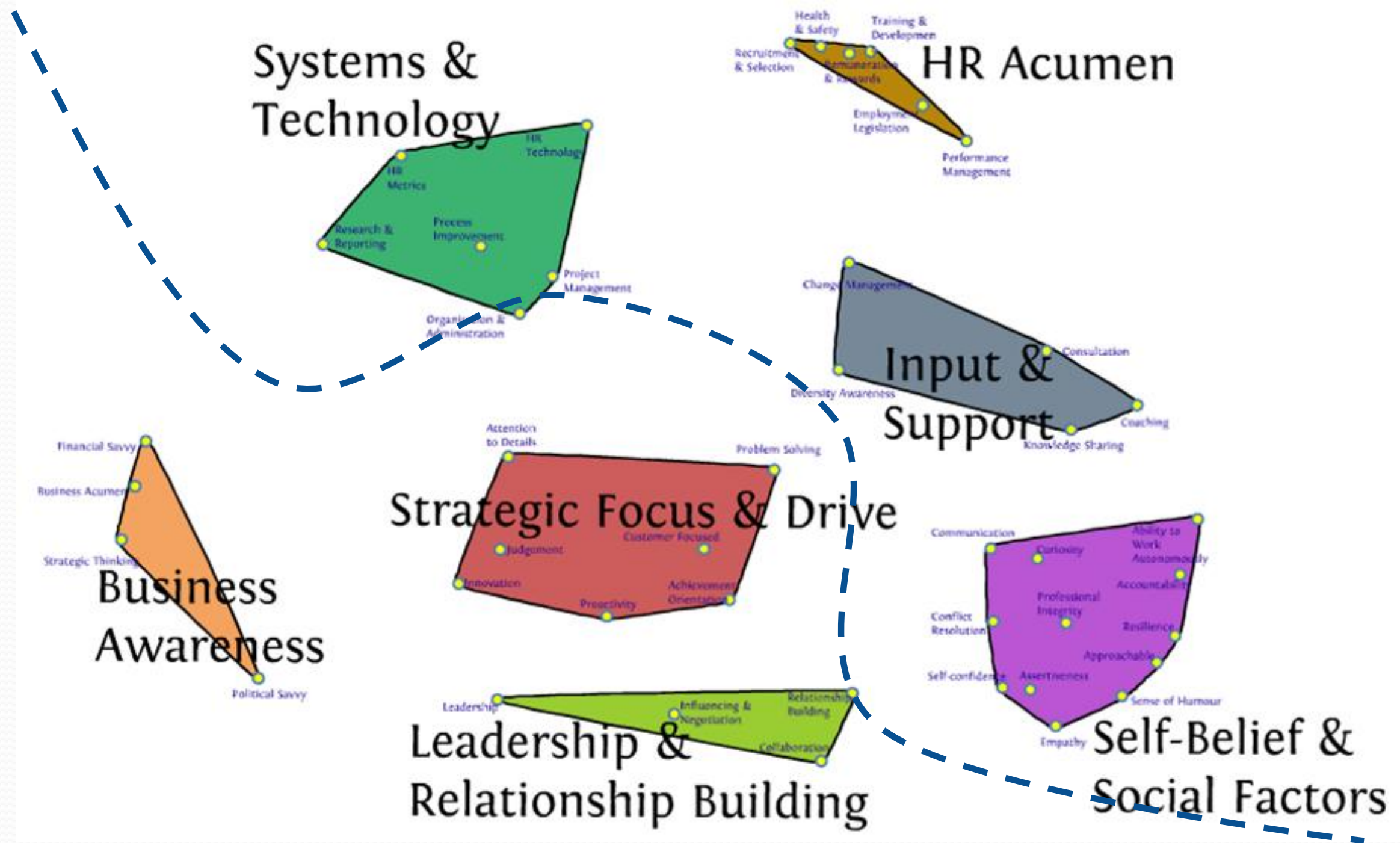




\section{Domestic Firms vs Overseas-based MNEs}

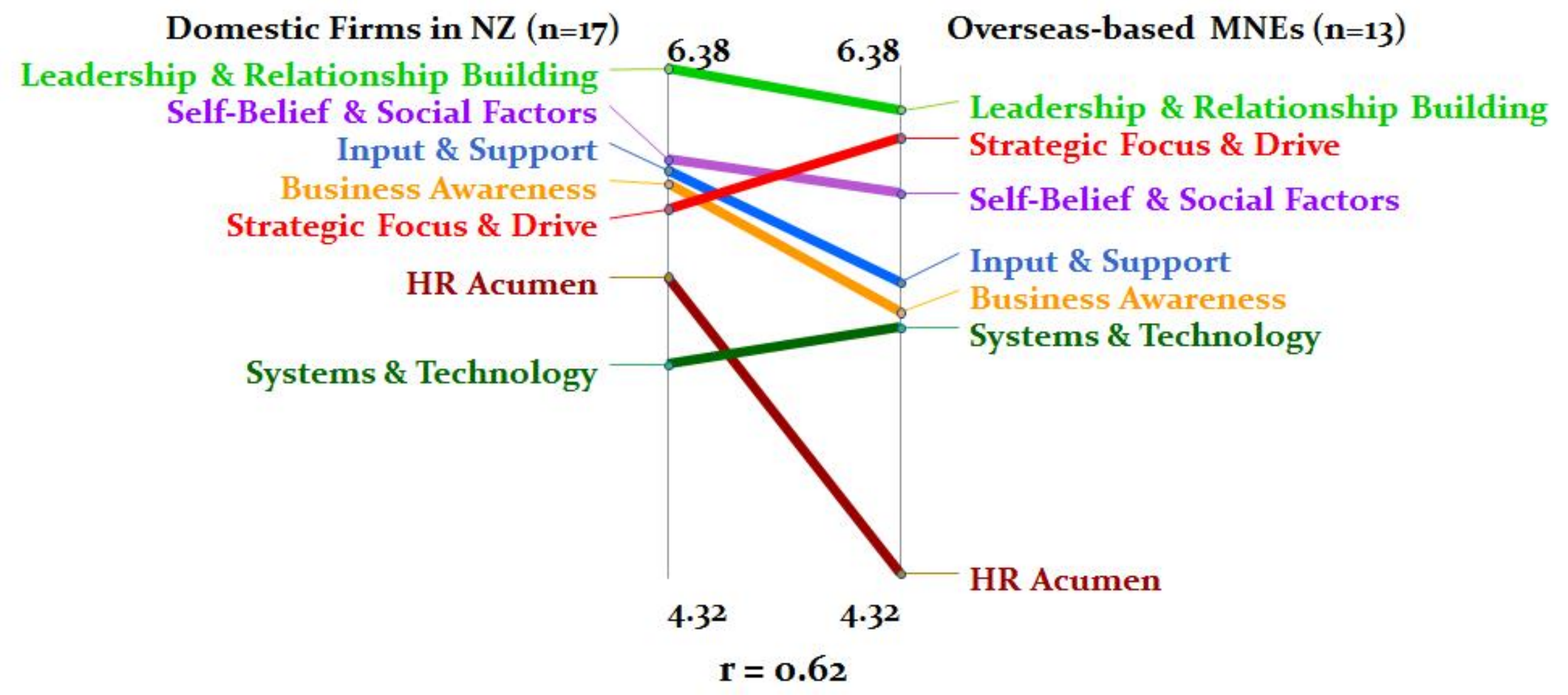




\section{Domestically based vs Overseas-based MNEs}

Domestically based MNEs $(\mathbf{n}=5)$

Leadership \& Relationship Building HR Acumen

Strategic Focus \& Drive Self-Belief \& Social Factors

Input \& Support

Business Awareness

Systems \& Technology

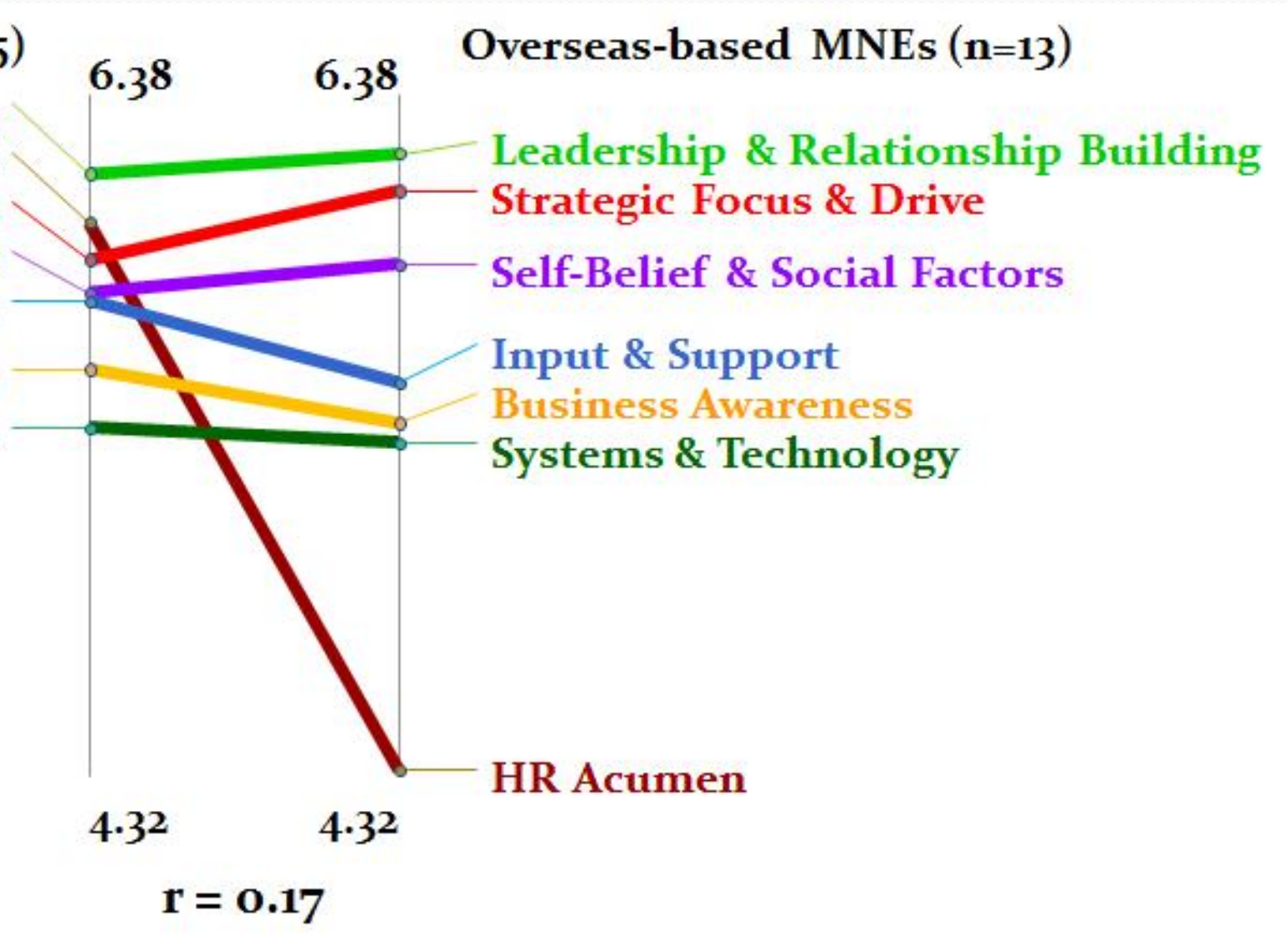




\section{Domestic Firms vs Domestically based MNEs}

Domestic Firms in NZ (n=17) Leadership \& Relationship Building

Self-Belief \& Social Factors

Input \& Support Business Awareness

Strategic Focus \& Drive

Systems \& Technology

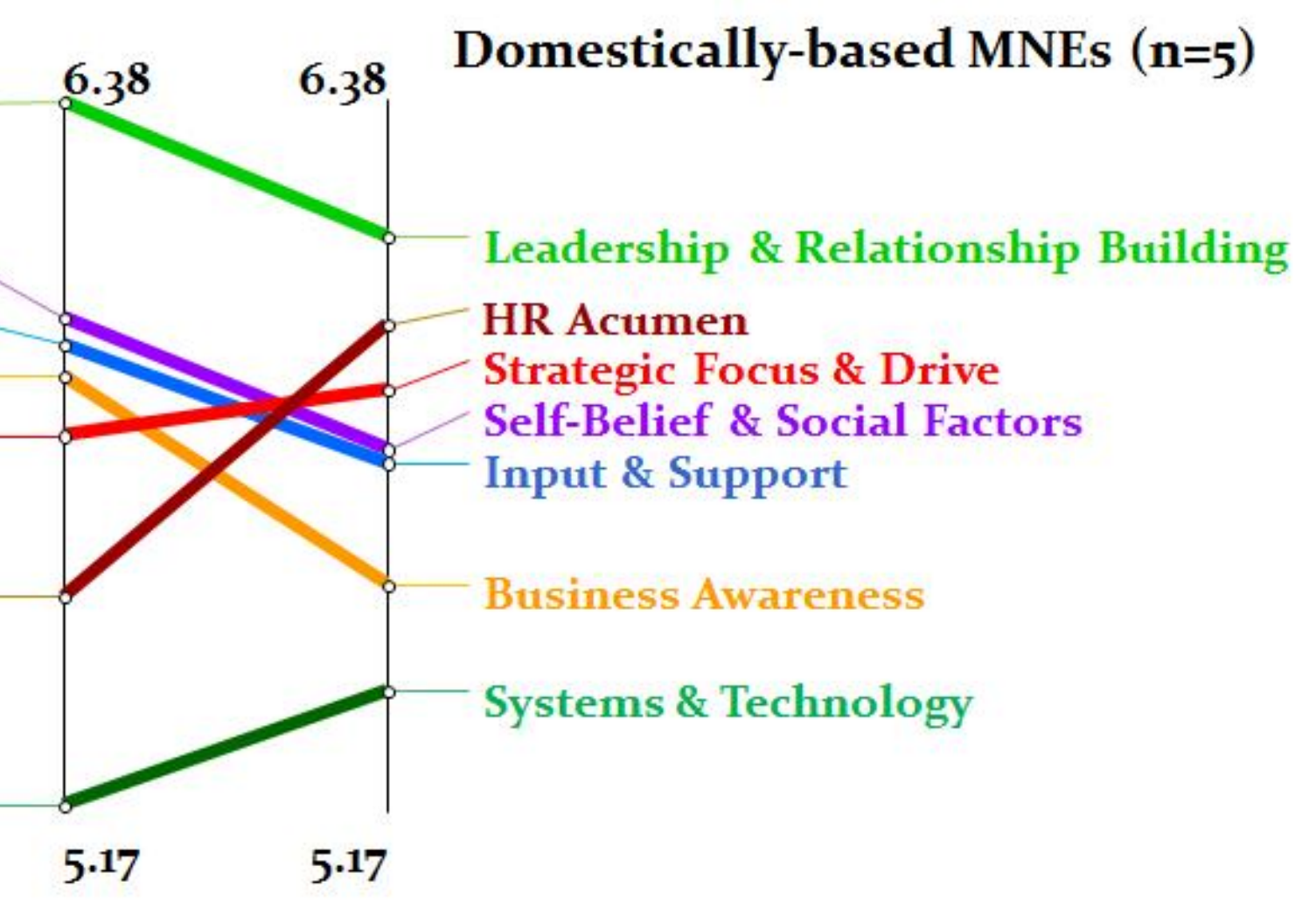

$$
r=0.64
$$




\section{Theoretical Contributions}

- Provides support for the situationalist approach

- Generic HR competencies: Leadership \& Relationship Building and Self-Belief \& Social Factors

- Context-specific HR competencies: HR Acumen

- Functional HR competencies can be as important as the strategic HR competencies required for adding value in certain contexts (Antila ,2006; Brown et al., 2009; Truss et al., 2002) 


\section{Practical Implications}

- HR Acumen competencies are highly context-specific

- Domestic firms and domestically-based MNEs are still highly dependent on HR generalist knowledge

- System and Technology are not important differentiators but MNEs make stronger use of knowledge in HR technology than domestic firms

- Importance of Leadership and Relationship Building and Self-Belief and Social Factors in the selection and development of HR practitioners 


\section{Research Limitations}

- Validate the research with a larger sample

- More international comparative studies of a more qualitative nature to get a more nuanced view of HR competency requirements.

- Include the opinions of other stakeholders (e.g., line managers, employees and trade unions) 


\section{THANK YOU}

Future research should move away from the one-sizefits-all universalist approach and adopt a situationalist approach to enable more nuanced understandings on what shapes HR competency expectations.

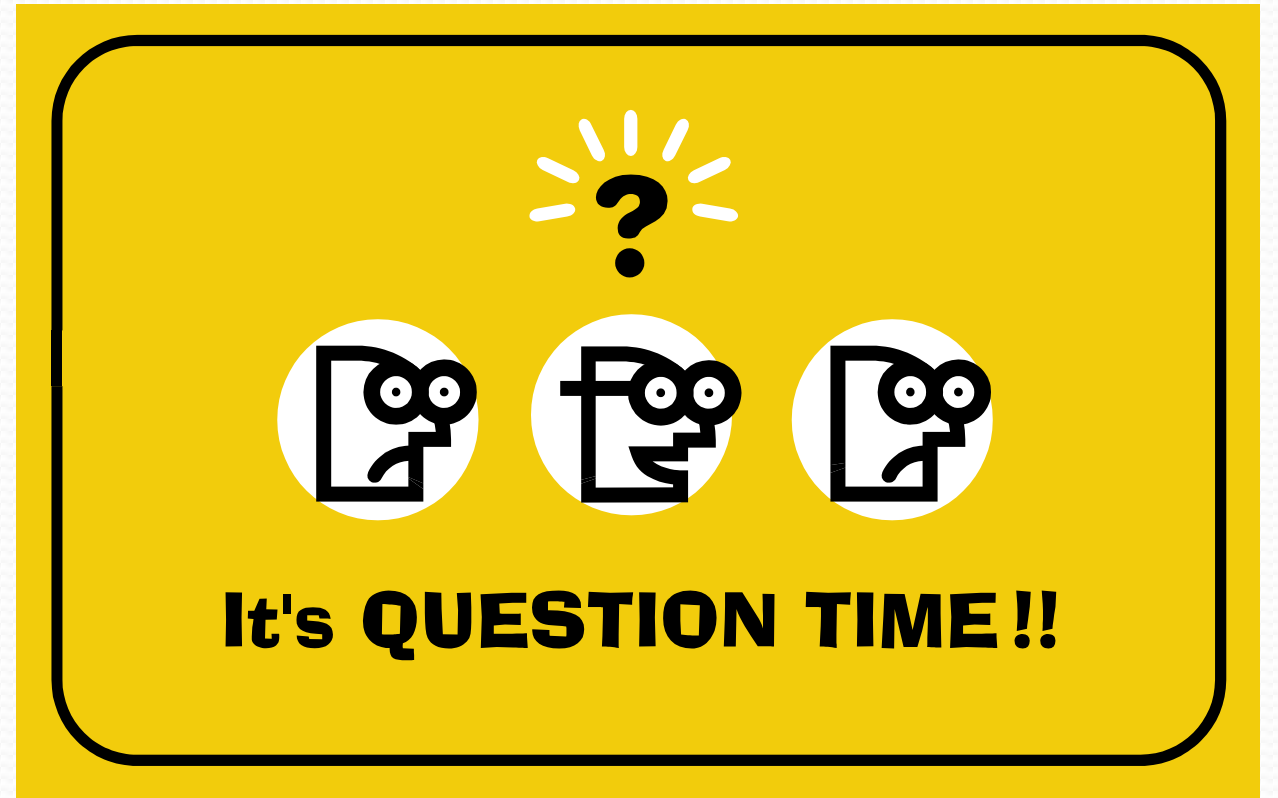

